\title{
ESCOLAS EM DEVIR: fabulações com vídeos em ocupações compartilhados na internet $e$ criação de outros currículos
}

\author{
Maria da Conceição Silva Soares \\ Universidade do Estado do Rio de Janeiro - UERJ \\ Vanessa Maia Barbosa de Paiva \\ Universidade Federal de São João del-Rei - UFSJ \\ Leonardo Nolasco-Silva \\ Universidade do Estado do Rio de Janeiro - UERJ
}

\begin{abstract}
Resumo
O texto se ocupa de vídeos sobre as ocupações de escolas públicas em 2016, produzidos por estudantes e postados no site de compartilhamento YouTube e na rede social Facebook, para pensar questões como autoapresentação, autorrepresentação, fabulações imagéticas e devir dos personagens reais que se propõem a ficcionar sobre si, sobre as escolas e sobre os currículos. Dialoga com Deleuze, Gonçalves e Head e Michel de Certeau, entre outros autores, para indicar essas produções como possibilidades de uso do que está posto e do que é imposto, de imaginação, ação e invenção, com e apesar das políticas de Estado para a Educação e das contingências de precariedade a que estão submetidas muitas escolas, tomando-as como micropolíticas cotidianas potentes para a criação de outros/novos/múltiplos currículos.
\end{abstract}

Palavras-chave: Ocupações de escolas. Vídeos. Fabulações. Criações curriculares.

\begin{abstract}
The present text is about videos on public school occupations which happened in 2016, produced by students and posted on the YouTube sharing site and on the Facebook. Its main purpose is to reflect over some issues, such as self-presentation, self-representation, image's fabulation and also, the real characters' becoming which aims to fictionalize about themselves, schools and curricula. The text dialogues with Deleuze, Gonçalves \& Head and Michel de Certeau, among other authors, indicating these productions as uses possibilities of whatever is already set and what is imposed; of imagination, action and invention, with/in spite of state policies for Education and the precarious contingencies to which many schools are subjected to, also taking them as potent everyday micro policies for the creation of other/new/multiple curricula.
\end{abstract}

keywords: School occupations. Videos. Fabulations. Curricula creations.

ISSN 1645-1384 (online) www.curriculosemfronteiras.org 
A imagem está fechada no rosto de uma menina. Seu rosto está pouco iluminado. Não sabemos ao certo onde foi gravada, se nos ambientes da escola ou em outro, porque o fundo nos parece mais claro. A câmera está fechada no rosto que diz sobre o que lhe transborda. Não podemos afirmar se o vídeo foi feito por celular ou por câmera de computador. Contudo, é uma imagem belíssima, porque não há imagem mais bela do que uma imagem que é produzida por uma câmera focada no rosto de uma pessoa dizendo o que ela acredita (MACHADO, 2002).

Esse texto é uma tentativa de pensar $\operatorname{com}^{1}$ e a partir dos vídeos de ocupações das escolas no Rio de Janeiro, no ano de 2016, produzidos por estudantes e publicados no site de compartilhamentos YouTube e na rede social Facebook. Faz parte de nossa proposta, ao longo deste artigo, pensar estes vídeos a partir das e com as fabulações de seus realizadores na produção de um devir escola e de um devir currículo. Tentaremos, também, pensar com e a partir desses conceitos, que serão melhor explicitados e apropriados. Por agora, gostaríamos que você pensasse nessa imagem descrita acima como se fosse uma música, uma melodia, uma poesia e conseguisse retirar dela sua beleza.

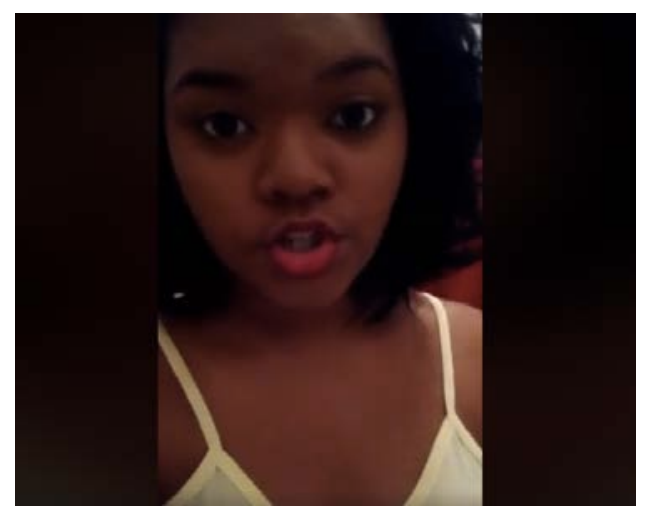

Figura 1. Print de filme produzido por estudantes e compartilhado no YouTube.

Disponível em: <https://www.facebook.com/OcupaMendes/videos/>. Capturado em: 11/05/2018.

Mas o que diz essa menina? Por que o que ela diz nos faz pensar em uma imagem bonita? Porque ela fala da vida. Da sua e da dos outros, em um vídeo pequeno que faz caber um mundo.

Primeiramente, bom dia. Eu queria dizer que eu estou muito triste por não estar tendo aula. Mas eu apoio cem por cento a greve, apoio cem por cento a ocupação. Porque também eu não aceito estudar nas condições que a gente tem. Ou melhor, que a gente não tem. Sem ventiladores, tirando os nossos ar-condicionado [sic], os nossos laboratórios... a gente não usa o laboratório de química, a gente não usa o laboratório de informática. E se é feito para nós, eu acho que a gente tem que usar! E já que a gente não está usando, eu acho que nada mais justo do que a gente chamar a atenção das autoridades pra [sic] ajudar a gente porque, como todos dizem, nós somos o futuro da nação e se somos o futuro da nação, o que que está acontecendo? Por que a gente está vivendo nessa precariedade? Então eu apoio 
cem por cento! Vamos lá! Ocupa Mendes! (Vídeo \#ocupaMendes Depoimento de uma aluna, 1 min. 23/03/2016).

Das muitas lições que tirou da obra de John Cassavetes, Gilles Delleuze (1990, p. 187) alertou-nos que o ato de assistir a uma filmagem deve nos levar a um interesse maior pelas pessoas do que pela filmagem em si, dos problemas de qualidade da filmagem. Deveríamos, segundo Cassavetes, nos interessar mais pelos "problemas humanos". "Para que as pessoas não passem para o lado da câmera, sem que a câmera passe para o lado das pessoas" (CASSAVETES apud DELEUZE, 1990, p. 187).

As imagens do vídeo \#ocupamendes Depoimento de uma aluna ${ }^{2}$ não nos levam para o caráter técnico da filmagem, mas para a sua fala necessária, para os sentimentos que tomam corpo em sua voz e transbordam toda uma frustração que, em vez de imobilizá-la e levá-la à estagnação, a levaram para a luta, para a denúncia séria, porém tranquila, da necessidade de uma ocupação de escola, uma necessidade de mobilizar autoridades, uma necessidade de apresentar à sociedade os problemas pelos quais passa a escola, uma vontade de potência para fabular outros currículos possíveis.

O depoimento da aluna instaura uma modalidade para o estatuto da narração, que é o da fabulação. A fabulação deixa de almejar a verdade, para se tornar falsificante. Não seria, de modo algum, “cada um com sua verdade”, mas uma variabilidade que remete ao conteúdo. A fabulação seria, na concepção de Deleuze (1990, p. 161), "uma potência do falso que substitui e destrona a forma do verdadeiro”. A forma do verdadeiro utilizada nas mídias corporativas, e quiçá nas escolas, a respeito dos estudantes é um verdadeiro que, em muitos casos, considera as crianças e os adolescentes desinteressados, relapsos, atrasados e sem interesse em “assuntos importantes”. O modelo de verdade preestabelecido teria sempre uma função julgadora, que necessariamente defende as ideias dos que dominam ${ }^{3}$.

É preciso libertar os personagens do modelo de verdade que os penetram, e encontrar ao contrário a pura e simples "função de fabulação" que se opõe a esse modelo. O que se opõe à ficção não é o real, não é a verdade que é sempre a dos dominantes ou dos colonizadores, é a função fabuladora dos pobres, na medida em que se dá ao falso a potência que faz deste uma memória, uma lenda, um monstro (DELEUZE, 1990, p. 182-183).

O vídeo \#ocupamendes Depoimento de uma aluna contraria a forma do verdadeiro, porque esta forma é unificante e tende a engessar as identificações possíveis de seu personagem, no caso, a estudante. E “a potência do falso não é separável de uma irredutível multiplicidade. [A forma] 'eu é outro' substitui o 'eu-eu'” (DELEUZE, 1990, p. 163). E, de fato, os muitos “eus” se transformaram em "outros” a partir de suas práticas e fabulações. E estas fabulações instauraram um movimento de escolas em devir que "é sempre de uma ordem outra que a da filiação. Ele [o devir] é o da aliança” (DELEUZE, 1997, p. 19).

A partir das alianças possíveis,outros estudantes iniciaram seus movimentos de ocupações em outras escolas. No vídeo Ocupação estudantil nos colégios Gomes Freire e 
Mendes de Moraes $^{4}$, duas jovens sentam-se lado a lado e começam a dizer sobre seus movimentos estudantis.

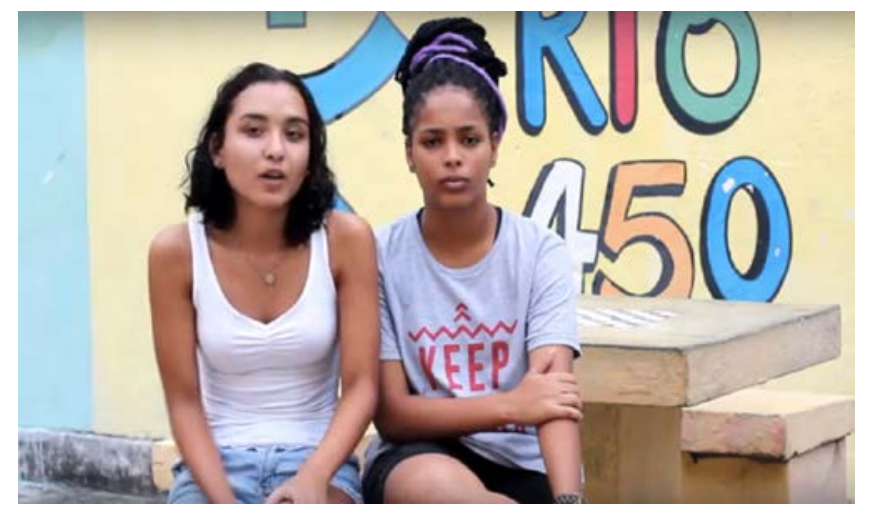

Figura 2. Print de filme produzido por estudantes e compartilhado no YouTube.

Disponível em: <https://www.youtube.com/watch?v=srVf2OyOnm4\&t=6s>. Capturado em: 11/05/2018.

A gente pensou: poxa, o pessoal do Mendes ocupou e a gente podia dar um apoio pra [sic] eles também, né? A gente já queria ocupar, a gente fez uma assembleia, chamou os alunos, conversou, perguntou, a gente fez uma votação nos turnos da manhã, da tarde, da noite pra [sic] ver o que os alunos pensavam sobre isso, até chegar o momento da gente ocupar mesmo (Nataly - Colégio Gomes Freire de Andrade).

Sua colega, Alessandra, sentada ao seu lado, complementa,

[...] a gente também quer parar os cortes na Educação, lutar pelos professores, a questão da acessibilidade, tipo a rampa do colégio, tem um degrau antes de você ter acesso à rampa e tem uma menina que é cadeirante. Ela não conseguiria se mobilizar sozinha aqui, no colégio.

Com estas narrativas percebemos bem o funcionamento da expressão "eu é outro". Eu estudante, sou outro, professor. Eu andante, sou outro, cadeirante. Eu sozinho, sou um grupo, uma assembleia, sou todos os alunos dos três turnos. Com esse vídeo, enxergamos que o que é visto e o que é falado entram em novas relações, uma vez que as formas da verdade foram substituídas por potências de vida (DELEUZE, 1990, p. 165).

\section{O que resta?}

Nos vídeos sobre ocupações, percebemos que restam os corpos, que são forças que enfrentam outras forças. O poder de afetar e de ser afetado, a relação de uma força com outras (DELEUZE, 1990, p. 170). E, na relação de forças, partimos para outro vídeo, gravado ${ }^{5}$ na 
escola Mendes de Moraes, que mostra um policial tentando entrar à força para desocupar o espaço.

Em uma imagem desfocada, vozes (que não são as dos policiais) se sobressaem: “vem aqui, gente, vem aqui”. Na imagem, o policial com o dedo em riste, diz: "isso aqui é do estado e eu quero a sua identidade. Se minha foto aparecer em algum lugar eu vou te acionar criminalmente”. O policial não consegue entrar na escola. Os alunos alegam que ele não apresentou mandado judicial. Ouve-se ao fundo a voz de um estudante que diz; "pô [sic], o cara tá aqui, um fuzil, cara, um fuzil”.

Neste vídeo, vemos que, em alguns casos, as forças são desiguais. Os policiais têm fuzil e os que estavam filmando dentro da escola, câmeras e celulares. Corpos de carne e osso; corpos tecnológicos, corpos bélicos e corpos estatais batalham pelo território escolar.

Em outro audiovisual, dessa vez, não produzido nas ocupações escolares, mas sobre as ocupações, uma reportagem do programa Cidade Alerta, da Rede Record, levada ao ar no dia 29/03/2016, anunciou que a Secretaria de Estado da Educação havia entrado com uma ação de reintegração de posse para paralisar a ocupação da Escola Mendes de Moraes.

Na tela, o então secretário de Educação do Estado, Antônio Vieira Neto, classificou o movimento dos estudantes da ocupação como partidário, alinhado com o movimento dos professores grevistas. Na entrevista gravada, o secretário afirmou: “a conversa está aberta, mas nós precisamos reestabelecer o funcionamento da unidade administrativa. Isso nos preocupa muito, porque nós temos alunos querendo ter aulas”. No mesmo vídeo, um jovem justifica o apoio aos professores: "eles estão sem receber, sem comida em casa. Eu poderia

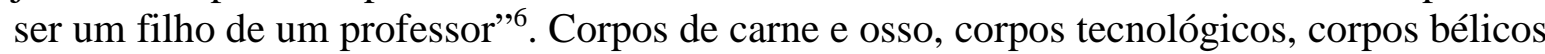
e corpos estatais. A relação de forças estava posta. O secretário de Estado da Educação afirmando que era necessário reestabelecer o funcionamento da unidade e os estudantes dizendo que poderiam ser filhos de professores que estavam sem receber e sem comida em casa. “Um golpe recebido, um golpe desferido” (DELEUZE, 1990, p. 170).

No vídeo Ocupa Irineu: os Minos ${ }^{7}$, realizado no Colégio Estadual Irineu Marinho (Duque de Caxias - RJ), a imagem de dois meninos franzinos se conjuga à imagem do exterior da escola, sem pintura, descascada e descuidada.

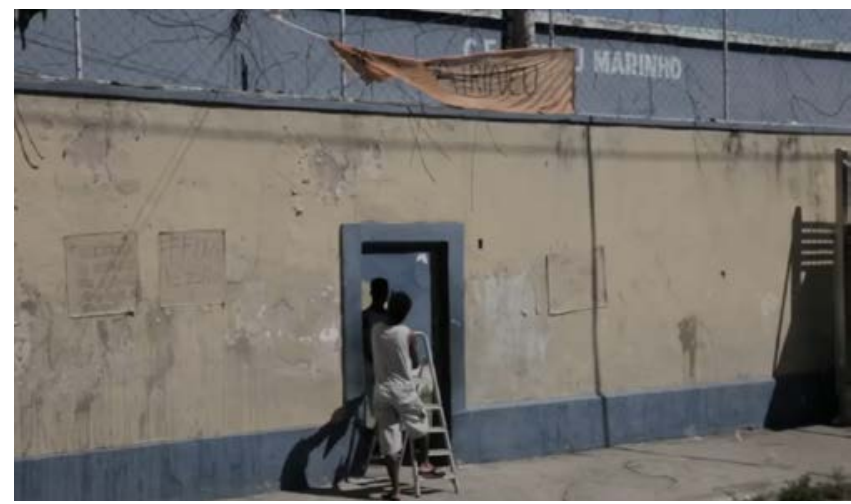

Figura 3. Print de filme produzido por estudantes e compartilhado no YouTube.

Disponível em: <https://www.youtube.com/watch?v=9KRIZ3_t2uA>. Capturado em: 11/05/2018. 
O primeiro aluno fala de si e, ao mesmo tempo, fala da escola. "Eu é outro". "Pra [sic] gente ter melhoria a gente tem que trabalhar, a gente tem que lutar. Não tem vitória sem luta". O outro complementa a fala e se lamenta: "A gente está esquecido. Eles esqueceram a escola. O estado esqueceu a escola. O governo esqueceu a escola".

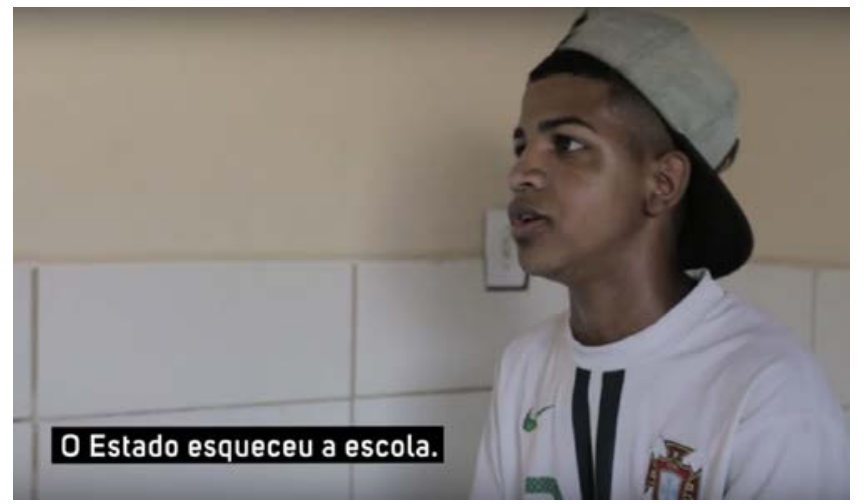

Figura 4. Print de filme produzido por estudantes e compartilhado no YouTube.

Disponível em: <https://www.youtube.com/watch?v=9KRIZ3_t2uA>. Capturado em: 11/05/2018.

Neste vídeo de ocupação, os alunos não foram identificados pelo nome. No som de fundo, um tic-tac de relógio mostrando que o tempo está passando para o Estado do Rio de Janeiro, para a Escola Estadual Irineu Marinho e, principalmente, para os meninos que poderiam recuperar muitas coisas, menos o tempo de suas vidas.

Ainda no vídeo, o menino franzino do início apresenta, orgulhoso, suas funções na ocupação: "arrumar a cozinha, limpar o banheiro e o nosso quarto. Tem que ter respeito aqui, porque é o local em que nós estamos convivendo. Ninguém vem aqui pra [sic] fazer bagunça”. Outro aluno, sentado, diz que está aprendendo muita coisa com a ocupação e, principalmente, sobre a questão do respeito. Citando o colega que falou antes, diz que quando este chegou à ocupação não dormia a noite inteira, mas que mudou. "Pô [sic], o cara mudou muito rápido".

Minutos depois, no vídeo, percebe-se que o menor dos problemas do menino que não dormia era a sua agitação noturna. Ele mesmo explicou sua relação com a escola: "eu preciso estudar. Eu moro em um lugar em que não dá pra [sic] ficar sem estudar...

\section{...Ou é a educação ou é o crime".}

Ouvimos a frase que já conhecíamos de ouvir falar, de tantas vezes contada, mas quando ouvimos o que transborda da voz do aluno, nos impactamos e lembramos de Nietzsche (1995, p. 18): “Quanta verdade suporta, quanta verdade ousa um espírito?”. O aluno do vídeo Ocupa Irineu: Os Minos ousou contar sua vida no vídeo, sem temer quem poderia assisti-lo, e quais as consequências que essa declaração poderia lhe causar em sua comunidade. 
Depois do impacto de sua fala: “ou a educação ou o crime”, ele continua,

[...] eu nunca fui um aluno exemplar, mas eu vejo que eu estou mudando, eu quero estudar, eu quero fazer um curso de direito, tem muitas coisas que a gente não sabe, que é do nosso direito: essas coisas de criança, o racismo, tem coisas que é do nosso direito e que nós não temos. Nós temos direito às coisas e nós não podemos, porque não é do nosso conhecimento.

O vídeo avança com sua beleza triste e os meninos continuam. Dessa vez, o amigo do jovem que quer estudar para conhecer seus direitos, começa a falar dos professores: "pô [sic], os professores escrevem com pilot que eles têm que comprar com o dinheiro deles. Pô [sic], aí não dá, né? Apagador? Com dinheiro deles. O álcool, com dinheiro deles. Aí não dá, né?”

Pela primeira vez, nos vídeos que assistimos e escolhemos para trazer para este artigo, aparece a fala de um professor. Até então, na maioria dos vídeos estavam os estudantes.

Eu sou professor de Geografia aqui da escola. Eu comecei um dia antes da greve. Eu comecei na terça-feira, a greve começou na quarta e, assim que eu cheguei, vi que tinha um movimento estudantil na escola. A gente debateu sobre a greve que iria acontecer e os alunos colocaram várias pautas da ocupação deles aqui, né? Eles relataram vários problemas que a escola tem, e a greve aconteceu. Eles se organizaram e conseguiram ocupar.

O vídeo retorna para o jovem que narrou a bifurcação de sua vida entre a educação e o crime. Agora ele fala com a segurança que só têm os que foram atravessados pela falta. Fala como se o corpo dele e o corpo da escola fossem apenas um. "Essa comunidade aqui, como é que se fala, que quando você precisa de amor, sabe? Uma comunidade carente! Tem gente carente de uma comunidade aqui. E eu sou um desses. Mas aqui tem muita gente, sabe? Daqui pode nascer jogador de futebol, pode nascer engenheiro”...

O outro estudante fala, "aqui na ocupação tem assembleia geral. Se eles juntassem todos os alunos e dissessem o que vocês têm a dizer, sabe? Dar ideia”. Nesse momento, no som de fundo do vídeo começa a se ouvir um som de batidas de coração. O colega dele complementa: "se o diretor pensasse, vou ouvir os alunos, vou ouvir o que eles têm de sugestão, o que eles têm de melhor pra [sic] nossa escola, o que eles têm pra [sic] interagir, pra [sic] ajudar”.

Não podemos dizer ao certo que os meninos estão assumindo um compromisso com tudo o que elencaram como propostas. Mas é justamente aí que reside a potência do falso, tal como propõe Deleuze (1990), porque essa potência atua como uma produção de imagens, sem ser um simples princípio de produção de imagens. Não seria um princípio de reflexão: atenção! Isso é escola! Mas seria "uma fonte de inspiração. [...] ou do possível, proceda ao impossível” (DELEUZE, 1990, p. 161).

O professor de geografia volta a falar no vídeo dos Minos:

É impressionante como eles mudaram em uma semana de ocupação. Tem um garoto que era um garoto problema na escola e ele está um ótimo garoto aqui. E 
assim, é um amadurecimento muito rápido, né? Um salto qualitativo de um pensamento de sociedade enorme, dentro dessa ocupação. Eu acho isso maravilhoso, né? Quando eu voltar pra [sic] dar aulas, será a melhor coisa do mundo também!”.

O vídeo termina com um som de um trem que está partindo. Ou que partiu.

Esse vídeo e os outros dois ${ }^{8}$ que foram aqui comentados apresentam currículos em devir com e a partir das fabulações contidas nos vídeos que foram elaboradas sobre/com elas. Um devir, segundo Deleuze (1990, p. 177), seria uma irredutível multiplicidade, em que as personagens ou as formas valem e atuam como transformações de umas nas outras.

\section{Um devir arte}

Mas o bom é a vida emergente, ascendente, a que sabe se transformar, se metamorfosear de acordo com as forças que encontra e que compõe com elas uma potência sempre maior, aumentando sempre a potência de viver, abrindo sempre novas possibilidades. Certamente não há mais verdade em uma que na outra: só há devir, e o devir é a potência do falso na vida, a vontade de potência. A criação de novas possibilidades é querer artista ou "virtude que dá", criação de novas possibilidades, no devir emergente. (DELEUZE, 1990, p. 173)

Poderíamos dizer, na realidade do trabalho em nossas escolas, que tudo o que foi dito pelos estudantes não condiz. Poderíamos afirmar que não é isso que vemos no dia a dia das salas de aula, dos pátios, dos corredores das escolas. Sim, poderíamos dizer, mas de maneira nenhuma podemos desconsiderar que os realizadores dos vídeos são, antes de tudo, criadores de verdades, "pois a verdade não tem que ser alcançada, encontrada, nem reproduzida, ela deve ser criada” (DELEUZE, 1990, 178-179). A verdade cria o novo. E o que seria o novo? A criatividade, a emergência. É aí, segundo Deleuze, que o falso atinge sua potência última: bondade, generosidade.

Notamos, ao longo dos muitos depoimentos que ouvimos, e vimos e sentimos, muita generosidade dos alunos com as escolas e com eles próprios, na mais bela forma do "eu é outro”. Limpeza, organização, produção de biblioteca ${ }^{9}$ para empréstimos, organizações de comissões para divisão de tarefas, problematizações sobre o racismo, o sexismo, a homofobia e outras formas de violência e discriminação que atravessam as práticas escolares e os conteúdos curriculares, preocupação com os professores e tantas outras "generosidades". Escolas que passaram a ter o devir cuidado, o devir político, o devir arte, que podemos ver no vídeo, de 32 segundos, sobre o ritmo do coco ${ }^{10}$ : "vamo [sic] ocupar com coco, com coco vamo [sic] ocupar, vamo [sic] ocupar com coco essa escola verdadeira, denunciar quem está fazendo besteira, estamos dançando coco, mas não estamos de bobeira. Vamo [sic] ocupar com coco, com coco vamo [sic] ocupar”.

Não podemos também deixar de mencionar as palestras que foram dadas nas escolas ocupadas, a visita do jongo, os debates sobre política e a conjuntura do estado do Rio de 
Janeiro, as conversas, a recreação, a unidade e a aposta na luta do coletivo. Em tudo isso, e em outros tipos de luta, reside a potência do falso que só é possível de existir porque uma série de potências estão sempre remetendo e penetrando umas às outras. (DELEUZE, 1990, p. 163).

As imagens, fixas, em movimento, frágeis, profissionais, quais sejam, segundo Gonçalves e Head (2009), adquiriram fundamental importância nas reflexões contemporâneas no campo das Ciências Sociais. As imagens são elementos que instigam novas/outras perspectivas sobre temas como a representação, a alteridade, a subjetividade, a individualidade e a imaginação (GONÇALVES; HEAD, 2009, p. 07).

Para o bem ou para o mal - estas mídias fotográficas, fílmicas, vídeos digitais e o imaginário "imagético" que elas animam já fazem parte do corpo etnográficociborgue que conecta Antropologia ao mundo dos outros e às representações e apresentações que estes outros fazem de seus mundos e do(s) nosso(s).

Por todos estes motivos elencados pelos autores acima citados e, ainda por nossa aliança com as áreas da Educação e da Comunicação, entendemos que os vídeos de ocupação de escolas são bons motivos para pensarmos com e a partir deles sobre temas tão presentes em nossos dias. Vídeos são compartilhados por telefones, tablets, computadores conectados à internet e tantos outros dispositivos. Assim também acontecem com os vídeos de escolas. Não foi (e nem entraremos nesse aspecto) nosso intuito avaliar enquadramentos adequados, captação de áudios perfeitos, tampouco origem do material de gravação (se câmera profissional, se câmera portátil, se celular ou tablet).

$\mathrm{O}$ que nos interessou pensar com esses vídeos das ocupações das escolas foi compreender o audiovisual como objeto sensível capaz de apresentar/representar relações com o outro, nas quais imagem e escrita de texto não criam um realismo, mas abrem caminho para a fabulação, para a ficção como forma de ampliar um tipo de conhecimento (GONÇALVES; HEAD, 2009, p. 17). Essa noção de que o audiovisual abre caminho para a fabulação, apresentada pelos autores citados acima, dialoga diretamente com Gilles Deleuze (1990), quando ele se propõe a pensar sobre o nosso modo de olhar as imagens audiovisuais.

Para Deleuze, o que devemos aprender com as imagens em movimento não seria a identidade dos personagens ali contidos, nem pelos seus aspectos objetivos, tampouco por seus aspectos subjetivos Deveríamos aprender com os audiovisuais a admirar o devir dos personagens e dos mundos em que habitam e criam quando eles se põem a ficcionar sobre si, sobre os outros, sobre a vida, pois “a personagem não é separável de um antes e um depois, mas o que ela reúne na passagem de um estado a outro. Ela própria se torna outro, quando se põe a fabular” (DELEUZE, 1990, p. 183).

Assim, o nosso desafio com esse texto foi o de tentar trazer um conjunto de vídeos nos quais seus personagens emergem a partir de uma concepção de autorrepresentação, que é "um modo legítimo de apresentar uma autoimagem sobre si mesmo e sobre o mundo. [...] um sujeito produtor de um discurso sobre si próprio”. (GONÇALVES; HEAD, 2009, p. 19). Entendemos, então, que os atos, os dizeres, os corpos, os anseios e as imagens apresentados 
pelos protagonistas dos vídeos das escolas ocupadas são valores que estudantes e professores representam para si mesmos (STTATHERN apud GONÇALVES; HEAD, 2009, p. 19).

Adotamos o conceito de autorrepresentação, de Gonçalves e Head, como conceito potente, porque ele se tornou um excelente interlocutor para nós, autores, porque este conceito fala dos que produzem "imagens sobre si”. A estudante que está no vídeo \#ocupamendes Depoimento de uma aluna diz que está triste por não ter aula, mas que apoia cem por cento o movimento de ocupação; o estudante do vídeo Ocupa Irineu: Dois Minos diz que nunca foi bom aluno, mas que quer fazer direito para conhecer muitos assuntos como o direito de crianças e negros. As jovens do vídeo Ocupação estudantil nos colégios Gomes Freire e Mendes de Moraes, estudantes da escola Gomes Freire, querem ser solidárias, seja com a causa da escola parceira, a Mendes de Moraes, seja com a colega cadeirante, que não consegue acesso sem ajuda dentro da escola.

Estes estudantes, ao produzirem imagens sobre si, produziram também um ponto de vista sobre uma escola, um currículo e um mundo que desejam. Como em um jogo de espelhos, produzem uma imagem de um mundo que eles desejam e uma imagem que desejam de si. Novamente aqui, entra o conceito de fabulação, porque faz emergir, na fala dos personagens, um processo de autorrepresentação que engendra questões estéticas e políticas. Talvez essa seja uma das possibilidades de emancipação na contemporaneidade: a fabulação imagética e, com isso, a invenção de si e do mundo, da educação, do currículo. Um modo de criar conhecimentos, significações e outros possíveis com e apesar das precariedades das escolas e das contingências das políticas de Estado para a educação. Talvez, essas criações de possíveis se constituam como experiências micropolíticas cotidianas.

Os vídeos de ocupação de escolas são potentes para que possamos pensar/sentir as escolas, a multiplicidade de escolas criadas nos cotidianos por seus praticantes (CERTEAU, 1994), porque eles não são representações realizadas por outros, pelos cinegrafistas profissionais, pelas mídias, pelas autoridades e/ou tantas outras instâncias que se outorgaram o direito de narrar o outro, de narrar a escola. Aqui, os praticantes dos cotidianos escolares, com os vídeos que produziram em diálogo e apropriação de múltiplas representações já constituídas sobre eles, se autorrepresentam, autorrepresentam seus mundos e se constituem em meio a esses processos.

A sensibilidade pós-moderna induz à proliferação das auto-representações em que as culturas e seus personagens se apresentam diretamente formulando seu ponto de vista e sua percepção sobre o modo que desejam ser representados e apresentados. [...] passam a falar sobre si próprios, se fotografam, se representam e apresentam em profundo diálogo com as múltiplas representações já constituídas sobre eles, o que engendra, por sua vez, curto-circuitos políticos e estéticos que movimentam novas formas de apresentação e de representação. Este novo contexto desestabiliza as "verdades" da representação antropológica, fazendo emergir fabulações dos personagens que se constituem através dos processos de auto-representação (GONÇALVES; HEAD, 2009, p. 20). 
Percebemos a potência das autoapresentações, das autorrepresentações e das fabulações dos estudantes, quando assistimos aos vídeos de ocupações das escolas porque deixamos de vê-los objetivamente. São, como disse Deleuze (1990), jovens que venceram a passagem ou as fronteiras, porque se inventaram (ou se autoapresentaram e se autorrepresentaram, como disseram Gonçalves e Head, 2009), como personagens reais. E se tornaram tão mais reais quando melhor se inventaram.

E o que é possível dizer sobre os estudantes que se autoapresentam ou se autorrepresentam, ao mesmo tempo em que apresentam/fabulam suas escolas, os currículos que almejam e criam, também dizemos dos realizadores dos vídeos de ocupações, que, no nosso caso, são estudantes e em outros, realizadores de audiovisuais. Também eles, que realizaram os vídeos, tornaram-se outros, na medida em que tomaram os jovens como intercessores e substituíram suas convicções pelas próprias fabulações dos estudantes (DELEUZE, 1990, p. 184-185).

Com Certeau (1995), entendemos os currículos, assim como a cultura, como redes de operações produtoras de significados e sentidos que formamos e que nos formam, tecidos no enredamento dos saberes-fazeres-poderes criados nos diferentes espaços-tempos cotidianos nos quais aprendemos, ensinamos e vivemos. Trata-se de operações de usuários do que está posto ou do que nos é imposto.

Currículos, conforme entendemos nas/com as pesquisas nos/com os cotidianos, são espaços-tempos de encontros com a alteridade, de estranhamento, de atribuição de sentidos e significações por meio de práticas negociadas, bricoladas e abertas à invenção e às oportunidades, nas contingências do que nos é imposto e nos oprime, do que produz afetos tristes e diminui nossa potência de criar e de viver uma vida afirmativa. Currículos são tecidos cotidianamente nas escolas, com os usos que fazemos de arbitrariedades políticas e teóricas e tentativas de controle. Os currículos praticados nas escolas são derivas de declarações de intenções institucionais, produtos de políticas públicas e decisões administrativas. São ainda derivações de corpos, mimeses de gestos, produção de desejos, inventividades e resistências daqueles que habitam os tempos-espaços escolares, com suas presenças - físicas e virtuais , ausências, temporalidades, astúcias, tensões, usos, enfim, com aquilo que não tem governo, limites, fronteiras. Os currículos praticados nas escolas, reiteramos, são tecidos em redes, no entrelaçamento de saberes-fazeres criados nos múltiplos contextos em que vivemos e aprendemos, entre eles as teorias educacionais, as políticas públicas, os usos das mídias, a experiência comunitária, o encontro com a alteridade, a fruição das artes, as vivências nos espaços da cidade e dos campos (ALVES, 2015), os agenciamentos os deslocamentos que produzimos e que nos produzem e os movimentos engendrados com as potências dos corpos. Os currículos são, também, o que fabulamos como imagens e sons, são o que somos capazes de imaginar e de praticar. São, portanto, os modos como organizamos e/ou desorgarnizamos as relações de saber-poder que nos despotencializam com os usos que fazemos do que nos é prescrito e limitante.

\section{Lettering ou à guisa de uma conclusão}


O Lettering é um recurso utilizado em vídeos para destacar frases ou palavras sobre os depoimentos que estão sendo gravados. É utilizado para enfatizar contextos que precisam ser destacados, para enfatizar a atenção, objetivando que ela não se dissipe. Assim sendo, pensando nesse texto como uma composição de texto-vídeo-música, em alguns parágrafos, iremos escrever na frente da frase: Lettering.Iniciamos este texto pedindo para que você volte a pensar na descrição da imagem do depoimento da primeira estudante mencionada, que está no vídeo de nome \#ocupamendes Depoimento de uma aluna, como se fosse uma música, uma melodia, tamanha a beleza que esse vídeo nos suscitou. Então, vamos trazer para finalizar a composição desse texto-vídeo-música uma letra do grupo Casuarina. Essa escolha não foi feita aleatoriamente. O grupo, que estava em turnê nos Estados Unidos, também gravou um vídeo em apoio às ocupações nas escolas do Rio de Janeiro.

Reunido em uma sala que aparenta ser um camarim, o Casuarina apoiou o movimento dos professores e estudantes, afirmando que

[...] esse é um movimento muito importante dos jovens que estão lutando por uma escola decente, uma escola melhor. Nada pode ser mais natural do que estudantes e professores ocuparem uma escola, onde eles deveriam estar ocupando normalmente. A gente tem que chamar os estudantes e professores para ocupar a escola. Escola é lugar de estudantes e de professores.

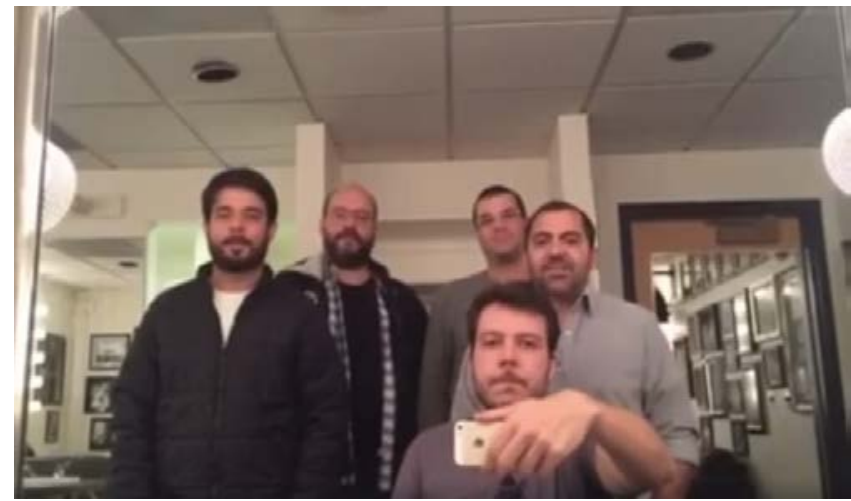

Figura 5. Print do Vídeo do grupo Casuariuna, gravado e enviado dos EUA em apoio ao \#ocupamendes. Disponível em: <https://www.facebook.com/OcupaMendes/videos/ 250330408654312/>. Capturado em:

11/05/2018.

Pretendemos, então, encerrar esse texto com uma música do Casuarina e outras composições textuais dos autores que nos inspiraram a escrevê-lo: músicos, filósofos, cineastas. A letra do Casuarina diz o seguinte:

Lettering: "Do ponto de vista da terra quem gira é o sol./Do ponto de vista da mãe todo filho é bonito./Do ponto de vista do ponto o círculo é infinito./Do ponto de vista do cego sirene é farol./Do ponto de vista do mar quem balança é a praia./Do ponto de vista da vida 
um dia é pouco./Guardado no bolso do louco./Há sempre um pedaço de deus./Respeite meus pontos de vista./Que eu respeito os teus./”

Do ponto de vista dos estudantes narradores nos vídeos das ocupações a escola é oportunidade de vida melhor, é amizade, é aprendizado, é troca, é saber, é solidariedade, é cuidado, é política, é estética, é literatura, é saber, é poder. Do ponto de vista dos estudantes a escola é devir. Devir artista, devir advogado, devir política. E um devir, como disse Deleuze (1997, p. 19), “não se reduz”.

Lettering: O movimento de ocupação das escolas públicas do Rio de Janeiro começou em março de 2016. A partir desta data, 65 escolas públicas foram ocupadas. As reivindicações dos estudantes foram desde melhores condições estruturais das escolas, passando por reformulações dialogadas do currículo e da utilização dos espaços da escola, pela suspensão dos cortes das verbas da educação, pelo pagamento dos salários dos professores, que estavam sem receber, até pautas singulares que variavam de escola para escola, levando em conta questões muito específicas.

Lettering: Os vídeos citados nesse texto foram retirados do Youtube, em cuja consulta (com a chave Ocupações em escolas) encontramos mais de 2.110 resultados referentes às ocupações em todo o país. Também utilizamos vídeos postados na página Mendes em Luta, elaborada pelo movimento \#ocupamendes.

Lettering: As ocupações nas escolas do Rio de Janeiro começaram em março de 2016 e terminaram em junho de 2016. Ao todo, 65 escolas foram ocupadas e mais de 50 mil estudantes foram envolvidos em decorrência das atividades de ocupação, conforme reportagem publicada no jornal on-line El País ${ }^{11}$.

Lettering: “Onde algo termina, onde começa outra coisa” (GODARD apud DELEUZE, 1990, p. 187).

\section{Notas}

1. Pensar com e não pensar sobre, reconhecendo que o pesquisador, ao olharouvirsentir o campo também olhaouvesente a si mesmo, com todas as suas redes. As pesquisas nos/dos/com os cotidianos partem desse princípio básico: nos cotidianos todos expressam alguma coisa, inclusive o pesquisador. As fabulações da pesquisa não podem desconsiderar a multiplicidade de vozes convertidas em palavras escritasfaladas pelo pesquisador em suas comunicações. Cf. Alves (2015); Ferraço (2003).

2. Disponível em: <https://www.facebook.com/OcupaMendes/videos/>. Capturado em: 11/05/2018.

3. A expressão utilizada textualmente por Gilles Deleuze (1990) é o ponto de vista do colonizador que nos levou à apropriação com a expressão do ponto de vista dos que dominam.

4. Disponível em: <https://www.youtube.com/watch?v=srVf2OyOnm4\&t=6s>. Capturado em 11/05/2018.

5. Disponível em: <https://www.youtube.com/watch?v=NO5C2l8ocSs>. Capturado em: 11/05/2018.

6. Disponível em: <https://www.youtube.com/watch?v=BG2i3ZVZgXU>. Capturado em: 11/05/2018.

7. Disponível em: <https://www.youtube.com/watch?v=9KRIZ3_t2uA>. Capturado em: 11/05/2018.

8. Vídeo 1)- \#ocupamendes Depoimento de uma aluna; Vídeo 2)-Ocupação estudantil nos colégios Gomes Freire e Mendes de Moraes, Vídeo 3)- Ocupa Irineu: os Minos.

9. Disponível em: <https://www.facebook.com/OcupaMendes/videos/246328842387802/>. Capturado em: 11/05/2018.

10. O vídeo leva o nome de dois emojis, em formato de coração $<3<3$. Um Emoji é uma forma de representação imagética que está presente em celulares, computadores e tablets. Configura uma linguagem examinada como uma comunicação 
não fonética. In: Emoticons, emojis e ícones como modelo de comunicação e linguagem: relações culturais e tecnológicas de Gláucio Henrique Matsushita Moro, publicado na Revista de Estudos da Comunicação, Curitiba, v. 17, n. 43, p. 53-70, set. /dez. 2016

11. Disponível em: <https://brasil.elpais.com/brasil/2016/04/29/politica/1461955632_442061.html>. Capturado em: $11 / 05 / 2018$.

\section{Referências}

ALVES, Nilda. Nilda Alves: praticantepensante de cotidianos.Organização e introdução Alexandra Garcia, Inês Barbosa de Oliveira. Belo Horizonte: Autêntica Editora, 2015. [Ttextos selecionados de Nilda Alves]

BERGSON, Henri. O pensamento e o movente. São Paulo: Martins Fontes, 2006.

CERTEAU, Michel de. A Invenção do Cotidiano: 1. Artes de Fazer. Trad.: Ephraim Ferreira Alves. Petrópolis, RJ: Vozes, 1994.

A cultura no Plural. Campinas, SP: Papiros, 1995.

DELEUZE, Gilles. Imagem-Tempo. São Paulo: Editora Brasiliense, 1990.

; GUATTARI, Felix. Mil Platôs - Capitalismo e Esquizofrenia. Trad.: Suely Rolnik. São Paulo: Editora 34, 2005. Vol. 4.

FERRAÇO, Carlos Eduardo. Eu, caçador de mim. In: GARCIA, Regina Leite. (Org.). Método: pesquisa com o cotidiano. Rio de Janeiro: DP\&A, 2003.

GONÇALVES, Marco Antônio; HEAD, Scott. (Orgs.). Devires Imagéticos - a etnografia, o outro e suas imagens. Rio de Janeiro: 7letras, 2009.

GUATTARI, Félix. Caosmose um novo paradigma estético. São Paulo: Ed. 34, 2006.

MACHADO, Arlindo. A televisão levada a sério. São Paulo: Senac, 2002.

NIETZSCHE, Friedrich. Ecce Homo - Como alguém se torna o que é. São Paulo: Companhia das Letras, 1995.

SOARES, Maria da Conceição Silva. Narrativas Audiovisuais, Redes Educativas e Diferença - Modos de Imaginar e de Significar o Mundo e de Reinventar as Práticas/Políticas Curriculares. Projeto Submetido ao edital Faperj/RJ, 2013-2014. 


\section{Correspondência}

Maria da Conceição Silva Soares: Universidade do Estado do Rio de Janeiro. Pós-Doutora em Educação (UERJ). Doutorado e Mestrado em Educação (UFES). Jornalista (PUC-RJ). Licenciatura em Sociologia (UFRJ). Professora Adjunta da Faculdade de Educação (departamento de Estudos Aplicados ao Ensino) e do Programa de Pós-Graduação em Educação, PROPED, na linha de pesquisa Cotidianos, Redes Educativas e Processos Culturais. Coordenadora do GRPESQ Currículos, Narrativas Audiovisuais e Diferença. Cientista Nosso Estado FAPERJ. Procientista UERJ.

E-mail: ceicavix@gmail.com

Vanessa Maia Barbosa de Paiva: Universidade Federal de São João del Rei. Doutora em Educação pela UFES-ES. Professora Adjunta, pesquisadora do Departamento de Letras, Artes e Cultura (DELACUFSJ) - Curso de Comunicação Social - Jornalismo. Integrante do Grupo de Pesquisa CNPq Currículos, Narrativas Audiovisuais e Diferença.

E-mail: vanesssamaia@gmail.com

Lenonardo Nolasco-Silva: Universidade do Estado do Rio de Janeiro. Pós-doutor em Educação pela UERJ. Doutor em Educação pela UERJ e em Literatura Comparada pela UFF. Professor adjunto do Departamento de Estudos Aplicados ao Ensino da Faculdade de Educação da UERJ. Vice-Coordenador do Grupo de Pesquisa CNPq Laboratório Educação e República (LER). Integrante do Grupo de Pesquisa CNPq Currículos, Narrativas Audiovisuais e Diferença.

E-mail: leonolascosilva@gmail.com

Texto publicado em Currículo sem Fronteiras com autorização dos autores 